\title{
Knowledge Mapping and Understanding of Economics: A Study in Malaysia
}

\section{Muhammad Hussin, Ray Crozier}

To Link this Article: http://dx.doi.org/10.6007/IJARBSS/v11-i2/8887

DOI:10.6007/IJARBSS/v11-i2/8887

Received: 18 December 2020, Revised: 10 January 2021, Accepted: 19 February 2021

Published Online: 28 February 2021

In-Text Citation: (Hussin \& Crozier, 2021)

To Cite this Article: Hussin, M., \& Crozier, R. (2021). Knowledge Mapping and Understanding of Economics: A Study in Malaysia. International Journal of Academic Research in Business and Social Sciences, 11(2), 813824.

\section{Copyright: (c) 2021 The Author(s)}

Published by Human Resource Management Academic Research Society (www.hrmars.com)

This article is published under the Creative Commons Attribution (CC BY 4.0) license. Anyone may reproduce, distribute, translate and create derivative works of this article (for both commercial and non-commercial purposes), subject to full attribution to the original publication and authors. The full terms of this license may be seen at: http://creativecommons.org/licences/by/4.0/legalcode

\section{Vol. 11, No. 2, 2021, Pg. 813 - 824}

Full Terms \& Conditions of access and use can be found at http://hrmars.com/index.php/pages/detail/publication-ethics 


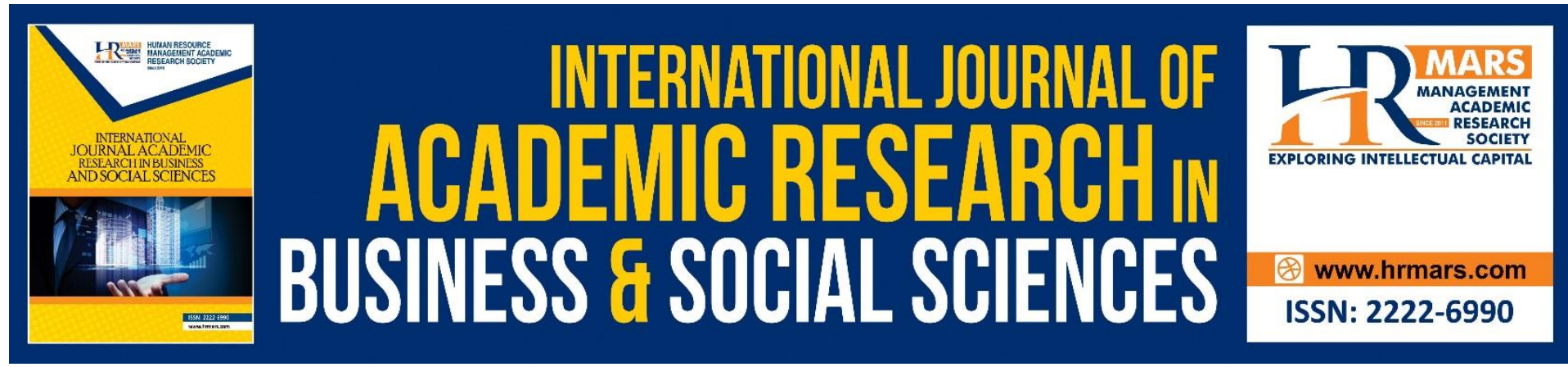

\title{
Knowledge Mapping and Understanding of Economics: A Study in Malaysia
}

\author{
Muhammad Hussin, Ray Crozier \\ Faculty of Education, Universiti Kebangsaan Malaysia, 43600 Bangi, Malaysia, University of \\ East Anglia, Norwich Research Park, Norwich, Norfolk, NR4 7TJ, UK \\ Email: r.crozier@uea.ac.uk,muhsin@ukm.edu.my
}

\begin{abstract}
An experiment to assess the effects of instruction in a knowledge mapping technique on students' learning performance in Economics was conducted in four secondary schools in the State of Selangor, Malaysia. Instruction in a note-taking technique served as a control condition, and a pre-test-post-test design was utilised. The study involved 135 Sixth-Form Economics students ( 24 males and 111 females) and four Economics teachers. The teaching of the knowledge mapping technique utilised the Knowledge Mapping Software for Teaching, Thinking, and Communicating developed by Dansereau and Cross (1990). The effectiveness of the technique was assessed by four types of assessment tests, two representing a lower level of understanding (MCQ1 and Cloze test) and two representing a higher level of understanding (MCQ2 and Essay test). The tests were developed on the basis of Bloom's taxonomy of educational objectives for the cognitive domain (Bloom, 1956), and followed the procedure suggested by Gronlund (1982). It was hypothesised that the knowledge mapping technique would assist students to perform better in the performance tests in comparison with the control group using the note-taking technique.

Keywords: Experimental Design, Knowledge Mapping Technique, Note Taking Technique, Cloze Test, Understanding Economic
\end{abstract}

\section{Introduction}

This study has its origins in concerns over attainment levels in Economics in schools in Malaysia. There is evidence that sixth-form students have not been performing well over many years in Economics in the Malaysian Higher School Certificate (equivalent to the British Advanced Level examination). Satisfactory performance on the Certificate is a prerequisite for entry into higher education and hence has a significant influence on the training of economists in Malaysia. For many years, students in Malaysian secondary school education have been under-achieving relative to their attainments in other areas of the school curriculum. In 1997, for example, 47 per cent of students obtained a pass (Principal levels A through $\mathrm{E}$ ) in the Certificate in Economics, which compares unfavourably with pass rates in other subjects; these range from 54 to 83 per cent, with a median of 60 per cent (Examination Council of Malaysia, 1997; Hussin, 1999). In some schools in rural areas fewer than $10 \%$ of candidates were successful in passing the Certificate in Economics. Relatively poor 
performance is evident even though these students have already undergone academic selection procedures at earlier stages in their school careers.

Several reasons have been proposed for this poor level of performance. Students, it is suggested, are weak in Mathematics and their lack of knowledge of the English language makes it difficult for them to study Economics reference texts that are written in English. Students also come to Economics late in their academic career relative to other subjects and steps have been taken to introduce it earlier into the school curriculum. The factor that is examined in this study, namely the learning strategies available to students, has been neglected in interpretations of student performance. This factor is often neglected in accounts of students' performance because instructors tend to assume that secondary school students already have these strategies and skills - 'One can repeatedly find teachers directing their students to a certain lesson or reading with nothing more than the instruction to learn the information, concepts, or skills contained. We tell our students what to learn but we say nothing about how to go about learning' (Weinstein, 1978, pp. 31-32). Research shows that study skills can be improved by explicit training in learning strategies and a number of these strategies have been developed in recent years. The principal aim of this study is to investigate the effect of instruction in one specific technique on students' ability to remember and comprehend an economics text. If it could be demonstrated that even a relatively brief training session could improve student performance this would suggest the potential value of fostering study skills for improving examination performance in Economics.

A number of techniques have been developed in recent years to help students apply explicit strategies for learning academic subject matter. These techniques draw upon findings from cognitive psychology, from research that has demonstrated that the implementation of strategies such as organisation of the material to be learnt and elaborative forms of rehearsal of the material results in more effective memorising (Groeger, 1997). The design of techniques has also been influenced by findings from the learning style literature in education, for example research that shows that an active and 'deep' approach to learning an academic text is more effective than a passive approach or an aim for verbatim recall (Marton \& Saljo, 1976).

The technique of knowledge mapping was developed by Dansereau (1978) in order to help students, learn textual material. Its emphasis on graphical representation of verbal material shares features with techniques of 'mind mapping' (Buzan, 1993) and concept maps (Novak, 1990) and has been influenced by cognitive psychological theories of long-term memory that construe memory as a network of concepts and their inter-relationships (Collins \& Quillian, 1969). Knowledge mapping is a general technique, not restricted to particular domains or subject matter, and focuses on helping the student to grasp the inter-relationships within the material to be learnt by drawing upon a standard set of nodes and labelled links in order to represent the key concepts of the text and their relationships. Students represent the material to be learnt by recasting it into a structural representation involving these nodes and links. The nodes depict key concepts and the links depict relationships among the concepts. Quite complex relationships can be represented as a number of different types of links can be incorporated into the maps. There are three types of links each with its own symbol for representation - dynamic, static, and elaborative links. Further 'sub-links' enable the student to represent other properties of a link, such as the strength of a relationship. For example, the dynamic link can be sub-divided into links depicting 'leads to', 'next, and 'influence'. Static links can be divided into 'type', 'part' and 'characteristic' links. Elaborative links depict 'example', 'analogy, or 'comment'. The maps that are constructed from nodes 
and links can be organised to represent different kinds of knowledge structures. For example, static structures can be hierarchical, cluster or chain-like, while dynamic structures can represent sequence, feedback loops, or causal relationships. It is apparent that knowledge maps can capture complex relationships among concepts and have wide applicability.

There is substantial empirical evidence of the effectiveness of knowledge mapping and related techniques (O'Donnell, Dansereau, \& Hall, 2002) provide a review of research. Knowledge mapping can be used in various ways. Students can learn the technique and apply it to learning academic material. Instructors can use the maps to help deliver complex material. Maps can also be used as a tool for communication, for example, in counselling (Czuchry \& Dansereau, 2003). O'Donnell, Dansereau, and Hall (2002) conclude their review of research by reporting that students recall more central ideas from material when they learn from a knowledge map than when they learn from text, although they do not necessarily recall more detail. There are individual differences in the tendency to benefit from the maps and students with lower verbal ability and less prior knowledge of the material benefit more than their more able or knowledgeable peers.

The focus of the study reported here is on instructing students in applying knowledge maps to their learning. Dansereau et al. (1979) reported superior learning of text material among a group of psychology undergraduates trained in knowledge mapping relative to a control group. Four tests of performance were included, a cloze test and an essay to assess the comprehension of main ideas, and short answer and multiple-choice questions to assess retention of detail. Significant benefits for the knowledge map group were found on the measures of comprehension but there were no differences between groups on tests of retention. The technique was more effective for students with low grade-point averages (GPAs) whereas there were no differences between knowledge mapping and control groups among students with high GPAs. This finding is consistent with the general trend in research that shows that less able or knowledgeable students make greater gains with knowledge mapping (O'Donnell, Dansereau, \& Hall, 2002).

The principal aim of this study is as follow:

- investigating the effectiveness of instructing students in Malaysia in knowledge mapping for improving learning of Economics material.

The method is to instruct a sample of students in the application of the technique to learning an Economics text and to compare their performance to that of a sample of their peers who are instructed in a standard note-taking technique.

The subsidiary aims are:

- to examine the influence of prior attainment in Economics and to determine whether the instruction of knowledge mapping has differential effects on alternative measures of performance.

It is hypothesised that students with lower prior attainments will benefit more from the technique than those with higher attainments. It is hypothesised that differences between knowledge mapping and a control condition will depend on the measure of performance examined, where performance is measured on a range of measures that are designed to assess higher order and lower order levels of understanding according to Bloom's influential taxonomy of educational objectives (Bloom, 1956). It is not possible to formulate a specific hypothesis about the nature of these differences given the paucity of research in this area. 


\section{Method \\ Participants}

The study was undertaken with permission of the Ministry of Education in Malaysia and school principals in four secondary schools, all located in suburban areas in the state of Selangor Darul Ehsan. All the schools had sixth-form Economics classes and all followed the standard national curriculum, including the same Economics curriculum. Students in two secondary schools participated in the knowledge mapping condition and students in the other two schools in the note-taking condition. Schools were allocated to treatment condition at random. Students completed the tests and training sessions within the classroom although the training involved some homework. At the beginning of the first test session participants were informed of the aims of the study and that it was being carried out for research rather than assessment purposes, and were assured of confidentiality.

The sample comprised 135 sixth-form Economics students, aged 18 or 19 years with mean age 18.32, 24 males and 111 females. Ninety-one students were Malay and 44 nonMalay (Indian and Chinese). The knowledge mapping condition comprised 70 participants (17 males and 53 females) and the note-taking condition 65 students ( 7 males and 58 females). The uneven gender distribution is representative of the sixth-form population and the uneven ethnic group distribution also reflects the distribution in the suburban areas in which the study was conducted. Malay and non-Malay students could not be allocated in equal numbers to treatment conditions and this is considered in the Results section below.

Four classroom teachers ( 3 male and 1 female) took part in the training sessions. All were Economics graduates and experienced teachers of the subject.

\section{Materials}

The text. The Economics text comprised a section of 1,870 words on international trade drawn from the textbook, Macro-Economy (Hamzaid, 1992). The topic was chosen because it was included in the Economics syllabus but had not yet been covered by the students participating in the study. A pilot study identified the time needed by students to complete reading of the text and established the word length of the section to be included in the main study.

Tests. Four tests - two multiple choice, one cloze and one essay test - were developed to assess understanding of the text. The tests were designed on the basis of Bloom's taxonomy of educational objectives (Bloom, 1956) with the aim of assessing different levels of understanding. The taxonomy posits a hierarchical order of categories from the simplest to the most complex outcomes - knowledge, comprehension, application, analysis, synthesis, and evaluation - with each category including the categories below it in the hierarchy. Knowledge and comprehension are classed as 'low levels' of understanding while application, analysis, synthesis and evaluation are classed as 'high levels' of understanding (Gronlund, 1982). The first multiple-choice test and the cloze test were constructed with the aim of assessing knowledge and comprehension. The second multiple-choice test and the essay task were constructed to assess application, analysis, synthesis and evaluation.

Development of the multiple choice items and essay questions involved specifying the general and specific learning outcomes to be attained and identifying the content areas to be tested, followed by drawing up a matrix of specification of outcomes and areas in order to ensure that items represented these. The general outcomes are based on Bloom's categories. For each of these, a set of specific outcomes is identified. Table 1 lists the general and specific outcomes adopted. The content areas were free trade, international trade, theory of absolute advantage, theory of relative advantage, effects of protective policy, and tariff, quotas and 
non-tariff protection. The matrix is used to ensure that test items assess outcomes and content areas in a systematic way with appropriate weight given to each outcome and area. In order to maximise fit between individual item content and the outcome it is intended to represent, the draft items were given to Economics teachers for comments.

Table 1

Table of Specification of Learning Outcomes and TextCcontent

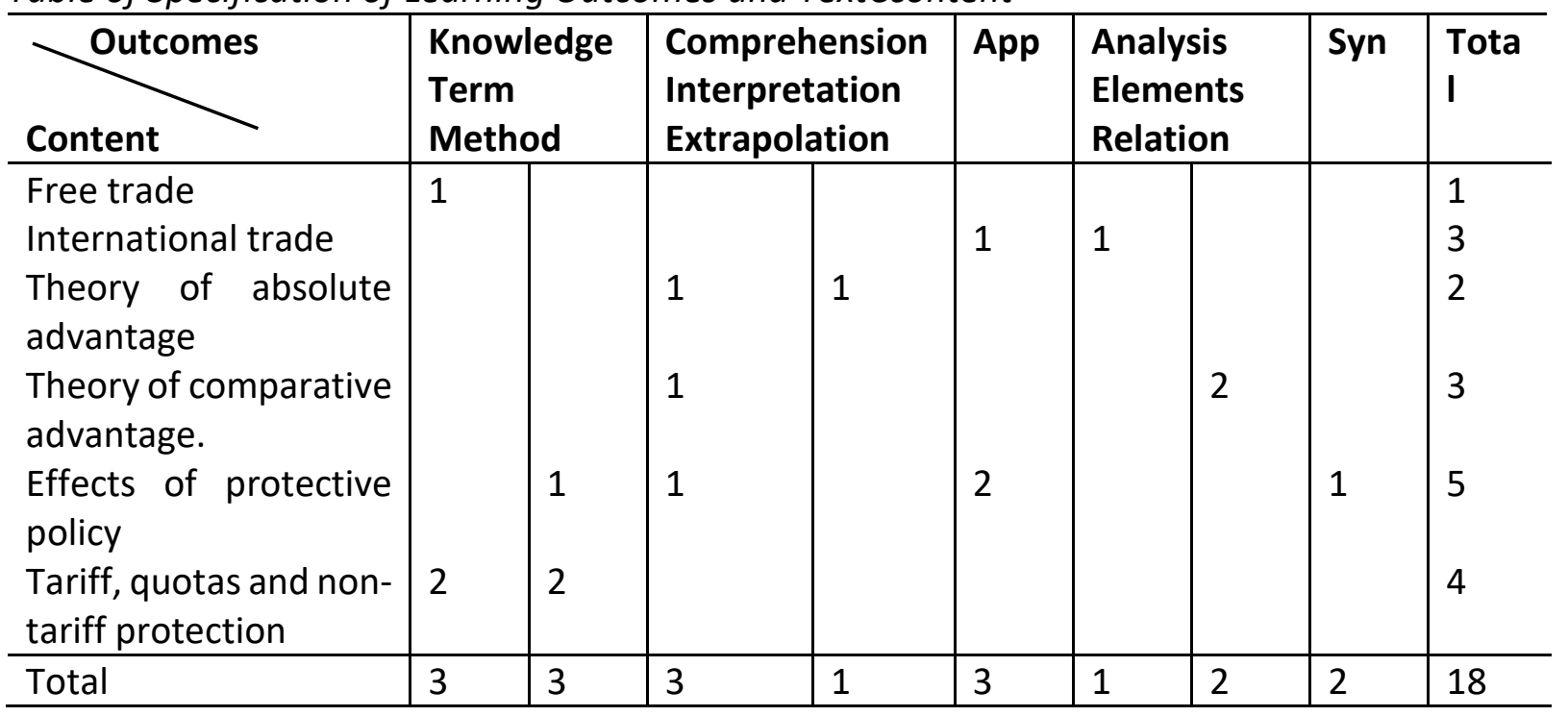

* App - Application

Syn - Synthesis

Multiple Choice 1. The test was constructed with the aim of testing recall of factual knowledge, terminology, methodology, interpretation and extrapolation. Each of 10 items had four response alternatives. The test was scored for percentage of correct items.

Multiple choice 2. The test was constructed with the aim of testing application, analysis, and synthesis. Each of eight items had four response alternatives. The test was scored for percentage of correct items. Item analysis was carried out for the set of 18 items following procedures advocated by Macintosh and Morrison (1969) to ensure that items had an appropriate level of difficulty and possessed sufficient discriminability. Items that were shown to be unsatisfactory in a pilot study were re-written to improve these indices. The reliability of items in the pilot study was satisfactory (Kuder-Richardson coefficient $=0.73$ ).

Cloze test. In a cloze test participant supply words that have been omitted from a passage and this is commonly used as a measure of comprehension (e.g., Rye, 1982). In this test 34 words were omitted from the summary passage of the text. The first sentence of the passage remained intact in order to provide necessary cues. Deletions of the passage were made for every seventh word from the second sentence. Scoring was as follows. Three points were allocated if the exact word was provided, two points for a word with the same meaning, and one point for a word that was grammatical. Words that were ungrammatical or where no response was made were assigned zero points. The score for the test was obtained by summing the number of points attained, diving this by the number of deleted words and expressing this as a percentage.

Essay. An essay test was included because of the difficulties of assessing evaluation using multiple-choice procedures and because it requires students to express their ideas and thoughts in a more complex way. Two essay questions were written to assess evaluation of 
the applicability of the theory of absolute advantage and the theory of comparative advantage and the practicality of protective policy. Students were expected to give the pros and cons of the protective policy. The essay was scored on the basis of a marking scheme provided by the researchers and undertaken by an experienced Economics teacher.

Economics attainment. A measure of Economics attainment was obtained from the student's examination results. Following Malaysian Examination Council procedures marks are assigned to one of five grades: very low (Fail), low (Subsidiary), medium (Principal E), high (Principal C and D), and very high (Principal A and B). Only students obtaining Principal E or higher are eligible for admission to study Economics or Business Studies in higher education institutions. Schools provided this information about participating students.

Knowledge mapping. Instruction was based on a manual published by Dansereau and Cross (1990). Prior to the main study a pilot study was undertaken to assess the appropriateness of this manual for these students. Discussions were also held with Economics teachers and on the basis of the pilot study and discussions there was some simplification of the language of the manual and some modification of links to make them more applicable to the subject matter. The 'next' link was replaced by a 'function' link and the 'analogy' link replaced by an 'assumption' link. Since the Economics text included many definitions of concepts the 'definition' link was added to the standard set of links. The modified manual provided the basis for instructing the students in knowledge mapping technique as described in the Procedure section.

Note-taking. A brief outline of the note-taking technique provided by Ferguson and O'Reilly (1977) was used to assist teachers in delivering the note-taking technique to participants in the control condition. The outline emphasised three steps in organising the material to be studied -get the central idea, separate central and secondary ideas, separate relevant and irrelevant information. Teachers and students were provided with illustrative examples of the application of these steps to economics.

\section{Procedure}

The design involved the sequence: studying the text task, completing tasks to test understanding of the text (pre-test), treatment, repeat studying the text, completing tasks to test understanding of the text (post-test). In the first session the text on international trade was distributed to students who were asked to read the instructions and to study the text for 35 minutes without taking notes. Students then completed the four tests on the text and completed questionnaires that do not form part of the study reported here. This session lasted for 2 hours 35 minutes. In the next stage, which took place on the following day, students were provided with training in either knowledge mapping or note-taking. The day after training was completed, the same text was distributed to students who were asked to study the text for 35 minutes using the technique on which they had been trained. This was followed by the four tests on the text; this session lasted some 2 hours 15 minutes.

The training sessions were provided by Economics teachers who had been briefed in the techniques by the researcher. Training included lectures and practice sessions and was organised according to a formal schedule to ensure that students had achieved mastery of the techniques. The knowledge mapping training lasted for 8 to 10 hours, including homework exercises. The note-taking training lasted 6 to 8 hours. The training concluded with an assessment exercise and a small number of students were omitted from the study because of poor attendance at the training sessions or poor performance on the knowledge mapping assessment. 


\section{Results}

The four tasks completed before and following the treatment were scored according to the procedure described in the Materials section. For each of the four tasks - Multiple Choice 1, Cloze, Multiple Choice 2, and Essay - gain scores were computed by subtracting pre-test from post-test scores. Inspection of the distributions of gain scores and pre-test and post-test scores showed no marked deviations from normal distribution and skewness and kurtosis indices were within the acceptable range. Inspection of the distribution of Economics attainment ratings provided by teachers suggested that the most meaningful split of the data to form an attainment variable was into a 'low attainment' group who had received ratings of 'very low' and 'low' $(\mathrm{N}=76)$ and a 'higher attainment' group receiving ratings of 'medium', 'high' or 'very high' ( $N=59)$. This essentially divides the sample into those predicted to fail and pass the Certificate examination.

Non-Malay participants obtained significantly higher pre-test scores than Malay participants on two of the four tests (Multiple Choice 1, $t=4.94, P<0.001$; Multiple Choice 2, $t=2.14, P<0.05)$. In order to assess the impact of these differences on gains, a repeatedmeasures ANOVA was undertaken with SPSS linear model programme, with gains on the four tasks as four levels of a repeated measures factor and experimental treatment (treatment vs control), Economics attainment (low vs higher) and ethnic group (Malay vs. Non-Malay) as between-subjects variables. None of the higher-order interaction effects involving ethnic group and treatment was statistically significant.

There was a significant task $x$ treatment $x$ Economics attainment interaction effect $(F$ $[3,125]=4.92, \mathrm{P}<0.01)$. In order to investigate this interaction more closely, and in the absence of significant interactions involving ethnic status, four two-factor ANOVAs were undertaken, one for each of the four tasks. Gain scores for the task comprised the dependent variable with experimental treatment and Economics attainment as factors. For Multiple Choice 1 task, there were significant main effects of treatment $(F[1,131]=8.26, P<0.01)$ and Economics attainment $(F[1,131)=18.53, P<0.01)$, qualified by a significant interaction term $(\mathrm{F}[1,131]=7.50, \mathrm{P}<0.01)$. Further tests showed that there was a significant difference between treatment and control groups for the lower Economics attainment group $(t=3.57$, $P<0.01$ ) but not for the higher attainment group ( $t<1.0, P=0.905)$. In summary, the treatment effect for this task is due to students of lower Economics attainment making greater gains than students of higher attainment.

For the Cloze task, there were significant main effects of treatment $(F[1,131]=15.92$, $P<0.01)$ and Economics attainment $(F[1,131]=7.65, P<0.01)$, qualified by a marginally significant interaction term $(F[1,131]=3.41, P=0.067)$. Further tests showed that there was a significant difference between treatment and control groups for the lower Economics attainment group $(t=4.46, P<0.01)$ but not for the higher attainment group $(t=1.41, P=$ 0.165). In summary, the treatment effect for the Cloze task is due to students of lower Economics attainment making greater gains than students of higher attainment.

There were no significant main effects or interaction effects for either the Multiple Choice 2 or the Essay task. Inspection of mean scores for these two tasks in Table 2 shows that the (non-significant) tendency is for students of higher attainment to make greater gains than students of lower attainment, in contrast to the trends for Multiple Choice 1 and Cloze tasks.

Gain scores can be less reliable than the scores from which they are derived and may be subject to ceiling effects and to regression to the mean effects (Gall, Borg, \& Gall, 1996). Because of these possible limitations of gain scores a separate approach to analysis was 
undertaken. A two-way analysis of covariance was undertaken for each of the four tasks, with post-test scores as dependent variable, pre-test scores as the covariate, and treatment and Economics attainment as factors. These analysed confirmed the findings from the gain scores, with the exception that the marginally significant interaction term in the Cloze test analysis reaches the conventional significance level $(F[1,130]=4.88, P<0.05)$, providing justification for the closer examination of the interaction term reported above. Again, there were no significant main effect or interaction terms for Multiple Choice 2 or Essay tasks. Mean (and standard deviation) pre-test and post-test scores are displayed in Table 2.

\section{Table 2}

Mean Scores and Gains Scores of the Knowledge Mapping Group and Note-taking Group for the MCQ 1, Cloze Test, MCQ 2 and Essay Test

\begin{tabular}{llll|lll}
\hline Scores & \multicolumn{2}{l|}{ Knowledge Mapping Group (n=70) } & \multicolumn{3}{l}{ Note-taking Group (n=65) } \\
\cline { 2 - 7 } & pre-test & post-test & gains scores & pre-test & post-test & gains scores \\
\hline MCQ1 & 54.57 & 83.29 & 28.71 & 58.77 & 79.69 & 20.92 \\
& $(17.59)$ & $(13.26)$ & $(13.72)$ & $(16.91)$ & $(12.86)$ & $(14.87)$ \\
\hline Cloze test & 53.44 & 61.60 & 8.15 & 50.68 & 53.31 & 2.64 \\
& $(9.11)$ & $(7.81)$ & $(6.81)$ & $(8.97)$ & $(8.96)$ & $(8.28)$ \\
\hline MCQ 2 & 33.21 & 44.46 & 11.25 & 36.15 & 44.42 & 8.27 \\
& $(13.61)$ & $(14.06)$ & $(13.98)$ & $(12.52)$ & $(12.30)$ & $(14.37)$ \\
\hline Essay test & 19.84 & 23.41 & 3.57 & 20.57 & 23.80 & 3.23 \\
& $(5.53$ & $(6.43)$ & $(3.73)$ & $(6.65)$ & $(7.10)$ & $(2.78)$ \\
\hline
\end{tabular}

\section{Discussion}

Analyses of measures of performance showed that students in the knowledge mapping condition made larger gains than students in the note-taking group, specifically on measures of what Bloom (1956) has termed 'lower levels' of understanding. Gain scores were significantly higher when knowledge and comprehension were assessed and while scores were also higher when application, analysis, synthesis and evaluation were assessed this difference did not reach the conventional statistical significance level. Students identified as having prior attainment that would not reach a pass level in the Certificate examination benefited significantly more from exposure to the knowledge mapping technique than did those who attained pass levels.

The superior performance of participants in the knowledge mapping condition is consistent with findings from previous research using knowledge mapping (O'Donnell, Dansereau, \& Hall, 2002) and also research with similar techniques - concept mapping in learning science (Elhelou, 1997; Novak, Gowin, \& Johansen (1983) and a spatial learning strategy in learning geography (Izhab, 1993). Research into student note-taking also shows the advantages of techniques that invite students to impose a representational structure on the material (Kiewra, 1991). Taken together, this research suggests the benefits for improving student performance in Economics of direct instruction in study skills; even a brief introduction to the knowledge mapping technique brings about an immediate improvement. Further research could usefully examine the long-term benefits of more sustained instruction. Clearly the technique requires an initial investment of time and effort on the part of the student (and instructor) but the benefits seem to outweigh the costs.

Knowledge mapping seems to improve some aspects of learning performance more than others. In this study larger gains were made on two of the four assessments. It is not 
straightforward to relate this to previous studies since they include a range of measures that are difficult to relate to each other. This study aimed to include measures in a systematic way, drawing upon a well-established theory of instruction (Bloom, 1956) and preparing tests with due attention to their psychometric properties and in consultation with Economics teachers. The specific gains identified here might reflect these features of the design of the study. Further research needs to include more intensive instruction and examine student progress over a more extensive period of time, as it might take longer to detect some of the benefits of the technique, particularly where 'higher levels' of understanding are concerned.

The finding that lower achieving Economics students benefit more from the technique is also consistent with previous research findings. It can be argued that students with less prior attainment in a subject may benefit more because they lack effective study skills. On the other hand, more successful students may have already developed effective study techniques and are not aided by acquiring a new one; alternatively, the acquisition interferes with their existing skills. However, there exists little direct evidence on this issue and this interpretation remains conjecture.

A single investigation of the short-term effects of a brief intervention provides only limited evidence in itself. Furthermore, there are clearly many reasons, to do with curriculum and forms of teaching and assessment, for example, why students of one academic subject in one country might do less well than expected. Nevertheless, the results of this study are encouraging and suggest the benefits of a focus on enhancing study skills and strategies, particularly for those students who are less likely to be successful in examinations. The study also extends previous research into learning strategies into Economics and into a country that has not hitherto been researched in this context.

\section{Conclusion}

This research has utilised a general-purpose strategy for learning an International Trade topic from Economics textbooks. Dansereau (1978) argued that the most important strategy dimension is the degree of specificity. In other words, future research on learning strategies should focus on training individuals in specialised strategies that are applicable to only a specific class of tasks. Although the strategy dimension might produce a built-in restriction on the generality continuum, it appears to be more cost-effective. Installing a specialised strategy training programme for learning skills does not appear to require very substantial resources. The cost to the school is small and it is not too demanding of time.

It is also suggested that future research should try to develop a strategy midrange on the generality-specificity continuum. This kind of strategy should be able to be employed effectively and also be general enough to have a relatively wide range of applicability. Such a learning strategy should either be content independent or content dependent and should relate to the actual mental manipulation of information to facilitate the cognitive processes of abstraction, assimilation, organisation and retrieval of academic information.

Future research into cognitive learning strategies should also focus on teaching the strategies to learners in the early years of intellectual development. This recommendation is based on the assumption that by successfully training children at an early stage to use a strategy, we can sometimes learn about the mechanisms involved in the ontogeny of strategy acquisition. The researcher believes that young children can also be successfully instructed to use many of the strategies previously thought to be available only to older children. 


\section{References}

Bloom, B. S. (1956). Taxonomy of Educational Objectives: Handbook 1: Cognitive Domain. New York: Longman.

Buzan, T. (1993). The Mind-Map Book. London: BBC Worldwide Ltd.

Collins, A., \& Quillian, M. R. (1969). Retrieval time from semantic memory. Journal of Verbal Learning and Verbal Behavior, 8, 240-248.

Czuchry, M., \& Dansereau, D. F. (2003). A model of the effects of node-link mapping on drug abuse counselling. Addictive Behaviors, 28, 537-549.

Dansereau, D. F. (1978). The development of a learning strategies curriculum. In H. F. O'Neil (Ed.), Learning Strategies (pp. 1-29). New York: Academic Press.

Dansereau, D. F., \& Cross, D. R. (1990). Knowledge mapping: Cognitive Software for Thinking, Learning and Communicating. Fort Worth, TX: Texas Christian University.

Dansereau, D. F., McDonald, B. A., Collins, K. W., Garland, J., Holley, C. D., Diekhoff, G. M., \& Evans, S. H. (1979). Evaluation of a learning strategy system. In C. D. O'Neil \& C. D. Spielberger (Eds.), Cognitive and Affective Learning Strategies (pp. 3-43). New York: Academic Press.

Elhelou, M. W. A. (1997). The use of concept mapping in learning science subjects by Arab subjects. Educational Research, 39, 311-318.

Examination Council of Malaysia. (1997). STPM Examination Report. Petaling Jaya, Malaysia: Longman Malaysia.

Ferguson, N., \& O'Reilly, M. (1977). Listening and Note-taking. Center for the Experimentation and Evaluation of Language Learning Techniques: Evans Brothers Limited.

Gall, M. D., Borg, W. R., \& Gall, J. P. (1996). Educational Research: An Introduction. New York: Longman.

Groeger, J. A. (1997). Memory and remembering: Everyday memory in context. London: Addison-Wesley-Longman.

Gronlund, N. E. (1982). Constructing Achievement Tests. Englewood Cliffs, NJ: Prentice-Hall. Hamzaid, Y. (1992). Ekonomi Makro (2nd ed.). Kajang, Malaysia: Pustaka Johami.

Hussin, M. (1999). The contribution of instruction in a knowledge mapping technique to students' understanding of economics texts. (Unpublished doctoral dissertation). University of Wales, Cardiff.

Izhab, Z. (1993). The efficacy of the spatial learning strategy in the recall and understanding of geography material. (Unpublished doctoral dissertation). University of Malaysia.

Kiewra, K. A. (1991). Aids to lecture learning. Educational Psychologist, 26, 37-53.

Macintosh, H. G., \& Morrison, R. B. (1969). Objective Testing. London: University of London Press.

Marton, F., \& Saljo, R. (1976). On qualitative differences I learning. I. Outcome and process. British Journal of Educational Psychology, 46, 4-11.

Novak, J. D. (1990). Concept mapping: A useful tool for science education. Journal of Research in Science Teaching, 27, 937-949.

Novak, J. D., Gowin, D. B., \& Johansen, G. T. (1983). The use of concept mapping and knowledge vee mapping with junior high school science students. Science Education, 87, 625-645.

O'Donnell, A. M., Dansereau, D. F., \& Hall, R. H. (2002). Knowledge maps as scaffolds for cognitive processing. Educational Psychology Review, 14, 71-87.

Rye, J. (1982). Cloze Procedure and the Teaching of Reading. London: Heinemann Education. 
INTERNATIONAL JOURNAL OF ACADEMIC RESEARCH IN BUSINESS AND SOCIAL SCIENCES

Vol. 11, No. 2, 2021, E-ISSN: 2222-6990 (c) 2021 HRMARS

Weinstein, C. E. (1978). Elaboration skills as a learning strategy. In H. F. O'Neil (Ed.), Learning Strategies (pp. 31-35). New York: Academic Press. 